\title{
Controle social na política de assistência social: um debate necessário
}

Social control in social assistance policy: a necessary debate

\section{Maciana de Freitas e Souza}

Bacharela em Serviço social pela UERN

Francisco Vieira de Souza Junior

Graduando em Direito pela UNIFACEX

\section{Debora Rute de Paiva Mota}

Bacharela em Serviço social pela UERN

\section{Resumo}

Este trabalho trata do controle social na política de assistência social. Com o objetivo de analisar como se configura o controle social da política de assistência social na realidade brasileira, o percurso metodológico privilegiou o uso de fontes bibliográficas e documentais. Compreendemos que houve avanços no que concerne ao exercício do controle social com a Constituição Federal de 1988, entretanto a mobilização e participação popular nos espaços de controle social precisa ser ampliada.

Palavras-chave: política de assistência social; neoliberalismo; controle social.

\begin{abstract}
This paper deals with social control in the social assistance policy. In order to analyze how the social control of the social assistance policy is configured in the Brazilian reality, the methodological approach privileged the use of bibliographic and documentary sources. We understand that there have been advances in the exercise of social control with the Federal Constitution of 1988, however mobilization and popular participation in social control spaces needs to be expanded.
\end{abstract}

Keywords: social assistance policy; neoliberalism; social control. 


\section{Introdução}

No Brasil, nas últimas décadas, com o processo de redemocratização política, podemos notar uma série de avanços sociais. Nesse contexto, emerge a política de assistência social, na Constituição Federal de 1988, como direito social. Historicamente, as ações eram restritas e “voluntárias", excluindo uma grande parte da população do acesso. É importante ressaltar que este reconhecimento constitucional se dá após anos de lutas sociais na esfera política.

É válido compreender que, apesar dos avanços com a Constituição Federal de 1988, a década de 1990 representou um período contraditório para as políticas sociais, com o desenvolvimento do projeto neoliberal, pois é notório o processo de desresponsabilização do Estado bem como a mercantilização dos serviços sociais públicos. Nesse sentido, cabe perguntar quais os rebatimentos do neoliberalismo para a efetivação dos mecanismos de controle e participação social?

A partir disso, nosso trabalho tem como objetivo compreender os desafios para o exercício do controle social no âmbito da política de assistência social. Quanto à metodologia, o estudo realizado utilizou uma pesquisa bibliográfica e documental, em sua maioria, teóricos do Serviço Social brasileiro que discutem a Assistência Social na cena contemporânea. Para tanto, nos apoiaremos na teoria social crítica de base marxista que se pauta numa abordagem histórica e dialética com base na totalidade social.

Este texto está dividido em três partes. Na primeira, apresentaremos algumas considerações conceituais sobre o controle social. Na segunda, buscaremos demonstrar a trajetória da política de assistência social. Em seguida, apresentaremos os desafios para o controle social, hoje, na realidade brasileira. Nas considerações finais, faremos breves apontamentos sobre a importância dos espaços de participação e controle social.

\section{Algumas considerações sobre o controle social}

Segundo Correia (2003), o termo controle social, inicialmente, foi utilizado na sociologia tendo como pressuposto o controle do Estado sobre a sociedade no sentido de manutenção da ordem vigente para viabilizar os interesses das classes dominantes. Nas palavras de Correia:

A expressão "controle social" tem origem na sociologia. De forma geral é empregada para designar os mecanismos que estabelecem a ordem social 
disciplinando a sociedade e submetendo os indivíduos a determinados padrões sociais e princípios morais. Assim sendo, assegura a conformidade de comportamento dos indivíduos a um conjunto de regras e princípios prescritos e sancionados. (2003, p.66-7)

Dessa forma, o Estado atuava no sentido de legitimar a ordem burguesa através do controle social numa tendência de integração, na busca de atenuar os conflitos e de garantir a sua legitimidade. Assim, o controle social se constituía como mecanismo básico de controle das classes trabalhadoras e, ao mesmo tempo, para a expansão e consolidação do capitalismo. Correia analisa que o controle social das classes subalternas se dá na medida em que a sociedade civil $^{1}$ organizada interfere na gestão pública, colocando as ações do Estado na direção dos interesses da coletividade.

Desta forma, o "controle social", na perspectiva das classes subalternas, visa à atuação de setores organizados na sociedade civil que as representam na gestão das políticas públicas no sentido de controlá-las para que atendam, cada vez mais, às demandas e aos interesses dessas classes. Neste sentido, o "controle social" envolve a capacidade que as classes subalternas, em luta na sociedade civil, têm para interferir na gestão pública, orientando as ações do Estado e os gastos estatais na direção dos seus interesses de classe, tendo em vista a construção de sua hegemonia. (2003, p.68)

Como ressalta o autor, a prática do controle social seria uma das vias pelas quais as classes subalternas têm a possibilidade de decidir e deliberar sobre as políticas públicas e, ao mesmo tempo, manter, por via do consenso democrático, o controle das ações estatais. "Esta classe deve ter como estratégia o controle das ações do Estado para que este incorpore seus interesses, na medida em que tem representado predominantemente os interesses da classe dominante." (2003, p.68).

Na sociedade civil, segundo Coutinho (2012, p.128), "as classes buscam exercer sua hegemonia, ou seja, buscam ganhar aliados para suas posições mediante a direção política e o consenso". Neste cenário, o controle social representa, pois, a capacidade que a sociedade civil tem de interferir na gestão pública com vistas à criação de políticas públicas. Tem-se, portanto, que o controle social se constitui num mecanismo democrático para que a população possa lutar

\footnotetext{
${ }^{1}$ (...) o espaço em que as classes organizam e defendem seus interesses (através de associações e organizações, sindicatos, partidos, etc.) é a esfera da elaboração e/ou difusão dos valores, cultura e ideologias que tornam ou não conscientes os conflitos e contradições sociais. Portanto, é nela em que se confrontam projetos societários, em que se desenvolve a luta pela construção de projetos hegemônicos de classe (DURIGUETTO, 2008, p.84).
} 
pela concretização dos seus direitos. Na mesma perspectiva, Machado menciona que o controle social:

Ocorre num cenário de disputa entre classes sociais para impor seus interesses na condução do Estado em busca da hegemonia. É movido por um movimento histórico, dialético e contraditório. De acordo com a correlação de forças do momento, ora tende estar do lado da classe dominante, ora das classes subalternas. O controle social, na perspectiva das classes subalternas, aconteceria no momento em que elas ocupassem e fortalecessem os espaços de organização da sociedade civil, ao buscar construir um projeto de classe contra-hegemônico capaz de gerar mudanças sociais (2012, p.53).

Com o processo de redemocratização política, os movimentos sociais organizaram-se no Brasil em torno de pautas voltadas à cidadania. Nesse período, foram dados os primeiros passos em busca de uma política mais democrática, de superação ao autoritarismo do regime militar. Essas lutas foram fundamentais para que a assistência social fosse considerada um direito constitucional, como também a participação social fosse inscrita na ordem estatal, com vistas a uma gestão pública compartilhada. Para Raichellis:

É nesse contexto que temas como descentralização, participação, democratização, fortalecimento da sociedade civil passam a emergir com força, na perspectiva de aumentar as vozes e os atores nos processos decisórios que interessam à sociedade, e enfrentar a tradição autoritária brasileira, presente não apenas no espaço estatal, mas nas múltiplas dimensões da vida social (2011, p.22-3).

A partir destes entendimentos, podemos considerar que o controle social numa perspectiva democrática representa a capacidade que a sociedade civil tem de interferir na gestão pública com vista à criação de políticas públicas a favor da classe trabalhadora. Entretanto, é importante analisarmos de forma crítica sem perder de vista que os conselhos são espaços de disputa política, portanto, podem contribuir para ampliação dos direitos sociais ou de legitimação do poder dominante. Como indicam Bravo e Correia:

Não são espaços neutros nem homogêneos, pois neles existe o embate de propostas divergentes para dar o rumo da política específica na direção dos interesses dos segmentos das classes dominantes ou das classes subalternas lá representadas. Isto significa que o controle social é uma possibilidade nesse espaço, dependendo da correlação de forças dentro dos mesmos, que, por sua vez, é resultante da correlação de forças existente no conjunto da sociedade civil. (2012, p.136). 
Mesmo sendo um espaço de interesses contraditórios, é imprescindível que a sociedade ocupe os espaços de participação política. Nessa perspectiva, é importante uma maior participação dos sujeitos e um amplo trabalho de capacitação para que ocorra uma intervenção qualificada e propositiva, com vistas a um controle social efetivo. Como indicam Carneiro e Gambi “(...) a participação social passa a ter um papel fundamental para se contrapor aos efeitos do neoliberalismo sobre os regimes democráticos" (CARNEIRO; GAMBI, 2018, p.79).

\section{A política de assistência social no Brasil}

A assistência social, no Brasil, foi vista durante muitos anos como "ação filantrópica", por intermédio do Conselho Nacional de Seguro Social (CNSS), criado em 1938, e da Legião Brasileira de Assistência (LBA), em 1942. Segundo Castro, “o CNSS e a LBA, podem ser considerados como as principais bases de legitimação do sistema em âmbito nacional, que se deu por meio das ações assistenciais" (2018, p.148).

Em uma perspectiva histórica recente, depois de muitas lutas, a assistência social é inserida na Constituição Federal de 1988, no âmbito da Seguridade Social e reconhecida como uma política pública, integrando, juntamente com as políticas de saúde e previdência, um sistema de proteção social. O artigo 203 determina que "a assistência social será prestada a quem dela necessitar, independentemente de contribuição à seguridade social” (BRASIL, 1988). No artigo 204, encontram-se duas diretrizes da política de assistência social, relacionadas à descentralização político-administrativa e à participação da população no âmbito dos conselhos.

Posteriormente, foi aprovada em 1993 a Lei Orgânica de Assistência Social (LOAS), reforçando sua dimensão enquanto política pública universal e de gestão participativa. No mesmo período, foi criado o Conselho Nacional de Assistência Social (CNAS). Dentro desta lógica de atuação estatal, os conselhos são formados por $50 \%$ de representantes da sociedade civil e 50\% de representantes do governo. Apesar das vantagens trazidas à população com esse ordenamento jurídico, é preciso analisar criticamente tais avanços, pois ainda persiste uma grande lacuna entre a legislação no plano formal e o que se esboça na sua concretização.

Como já mencionado, no Brasil, a partir dos anos de 1990, percebe-se o desenvolvimento do neoliberalismo sobre as políticas públicas e, a partir daí, dificuldades emergem para a efetivação de um projeto político que considere os reais interesses da classe trabalhadora. Nesse sentido, assinala Yazbek: 
(...) as transformações societárias resultantes das mudanças nas relações entre capital e trabalho, do avanço do neoliberalismo enquanto paradigma político e econômico globalizado vão trazer para o iniciante e incipiente campo da Seguridade Social brasileira profundos paradoxos. Pois, se de um lado o Estado brasileiro aponta constitucionalmente para o reconhecimento de direitos, por outro se insere num contexto de ajustamento a essa nova ordem capitalista internacional (2007, p.92-3).

Em 2004, foi aprovada a Política Nacional de Assistência Social (PNAS), cujo principal objetivo é a estruturação dos serviços da política em âmbito nacional, estadual e municipal, a partir do Sistema Único de Assistência Social (SUAS) e suas proteções sociais (básica e especial, de média e de alta complexidade). O SUAS estabelece, também, que o controle social deve ser compartilhado entre o Estado e as organizações da sociedade civil. Tais instrumentos constituem avanços significativos para a assistência social.

Nessa conjuntura, durante os governos de Lula e de Dilma Rousseff, podemos notar um investimento crescente em programas sociais, como, por exemplo, o Bolsa Família. Algumas mudanças importantes ocorreram, resultado direto das condições apresentadas na área da saúde e educação. Todavia, Mota, ao abordar o neodesenvolvimentismo ${ }^{2}$ dos governos do Partido dos Trabalhadores, afirma que, ao mesmo tempo em que cumpre tarefas democráticas, "a pobreza aparece distanciada dos debates estruturais e é transformada num objeto técnico em si” (2012, p.181).

Após o Golpe de Estado de 2016, que resultou na saída da presidenta Dilma Rousseff, com a ascensão do governo de Michel Temer podemos notar mudanças em torno da área social. Nesse contexto, observa-se a integração do Ministério de Desenvolvimento Social e Agrário (MDSA) bem como ações que fazem retornar o conservadorismo, a exemplo do Programa Criança Feliz ${ }^{3}$, que tem a primeira-dama como embaixadora. Como assinala Sousa, "além disso, as estruturas das políticas sociais públicas sempre foram configuradas por relações clientelistas, patrimonialistas, regadas pelo favoritismo político" (2013, p.184).

\footnotetext{
2 [...] o neodesenvolvimentismo é o projeto de desenvolvimento compatível com o atual regime de acumulação, que, para garantir o processo de valorização do capital, emprega uma política de criação de condições macroeconômicas para o crescimento da economia capitalista. Por outro lado, para enfrentar as consequências nefastas do capitalismo hipertardio e seu regime de acumulação destrutiva, constitui as bases de um novo padrão de enfrentamento da questão social que centraliza, sobremaneira, os programas de alívio à pobreza (Silva, 2014, p.388-9)

${ }^{3}$ O Programa Criança Feliz foi criado pelo Decreto n. 8.869, em outubro de 2016: "Art. 1. ${ }^{\circ}$ Fica instituído o Programa Criança Feliz, de caráter intersetorial, com a finalidade de promover o desenvolvimento integral das crianças na primeira infância, considerando sua família e seu contexto de vida, em consonância com a Lei n. 13.257, de 8 de março de 2016".
} 
Neste cenário, podemos observar ainda a aprovação pelo Senado Federal da Proposta de Emenda à Constituição (PEC) no 95/2016, que determina o congelamento dos investimentos públicos pelos próximos 20 anos, em que as políticas de seguridade social (Previdência social, Assistência social e Saúde) terão seus orçamentos reduzidos, o que se constitui um desafio para a garantia e expansão dos direitos sociais.

Observamos, também, mudanças no Benefício de Prestação Continuada (BPC), como a ampliação da idade mínima para sua concessão. Como apresenta Castro, "a partir de um contexto de 'ofensiva neoliberal' e de dissonância dos textos normativos se formata uma política de assistência social focalizada, distributiva com função principal de legitimar o sistema vigente" (2018, p.171).

A Síntese de Indicadores Sociais (SIS) do IBGE, divulgada no fim de 2018, mostra que, entre 2016 e 2017, a proporção de pessoas pobres no Brasil subiu de 25,7\% para 26,5\% da população, o que caracteriza um aumento de 2 milhões. Já o grupo dos extremamente pobres cresceu de 6,6\% da população em 2016 para 7,4\% em 2017, passando de 13,5 milhões para 15,2 milhões. Na perspectiva de Katz:

Nos últimos anos, este modelo aprofundou os abusos contra os trabalhadores em contextos recessivos que potencializam o temor e a miséria. A desigualdade social alcançou níveis sem precedentes, a pobreza expandiu-se nas economias centrais e a precarização do trabalho foi massificada em todo planeta. (2016, p.80)

Nesse contexto, observa-se que as necessidades sociais não têm sido prioridade da atuação estatal e que faltam propostas sérias e eficientes para a solução de problemas econômicos e sociais. Essa dinâmica também reflete no processo de despolitização. No entendimento de Carneiro e Gambi, a "distância social cria fortes barreiras de relação entre indivíduos e grupos, ou seja, quanto mais afastadas socialmente as classes, menor a probabilidade de construir relações e interesses comuns" (2018, p.80).

Portanto, com o avanço neoliberal e os desmontes de direitos em curso no Brasil, tornase necessário que a sociedade civil ocupe os espaços de controle social e construa ações de resistência ao poder constituído com vistas a melhorias nas condições de vida da população. Desse modo, a "participação social seria um instrumento, portanto, contra-hegemônico, já que permitiria a inovação democrática com a inclusão de temas ignorados pelo sistema político e geraria a sensação de pertencimento" (CARNEIRO; GAMBI, 2018, p.82). 


\section{O Controle Social hoje na realidade brasileira}

É importante ressaltar que a crise global do capital que repercute nos dias atuais teve seu impacto mais expressivo no final da década de 1970, com mudanças estruturais no processo de produção capitalista e no campo das relações sociais. Neste contexto, se estabelecem mecanismos de subordinação do Estado ao mercado. Essa articulação acaba refletindo na qualidade dos serviços públicos prestados aos usuários, como também repercute nos espaços de participação social. Nas palavras de Carneiro e Gambi:

Com efeito, apesar da perda de legitimidade do sistema representativo, do próprio esvaziamento do poder político, exercido pelo grande capital e por agentes externos, da grande desigualdade social existente e das crises econômicas que minam o debate democrático, a ampliação do processo da participação e do diálogo social institucionalizado tem sido apresentada como possível solução para os limites da democracia representativa, como no caso dos conselhos econômicos e sociais criados em diversos países no período neoliberal. (2018, p.84)

Nesse sentido, concordamos com Castro (2018, p.212) que, na realidade brasileira, a “escolha pelo Estado mínimo se expressa na política nacional de assistência social pelo singelo financiamento, pela focalização dos programas e serviços, pelo apelo às parcerias (...) em detrimento da universalização dos direitos sociais e da cidadania". Tal contexto fica evidente com as ações em curso, instituídas com objetivo de reduzir os direitos da classe trabalhadora e promover o desmonte dos serviços e benefícios já implantados.

Dado que o cenário atual impõe inúmeras adversidades, (re)pensar as políticas públicas no atual contexto, debatendo os principais desafios e possibilidades, torna-se fundamental. Neste processo, mesmo com o seu caráter contraditório, compreendemos os conselhos como espaços necessários para a democracia e ampliação dos direitos sociais. Segundo Carneiro e Gambi (2018):

De fato, o diálogo social se mostra essencial para tentar encontrar pensamentos inovadores, para além de políticas neoliberais como os ajustes fiscais, possibilitar a concertação social e motivar a participação dos cidadãos nas decisões políticas. Mais do que isso, faz-se necessária a rediscussão do aspecto moral da democracia, sem se centrar apenas em procedimentos. Para que isso ocorra, é importante a redução da desigualdade política e a garantia de sistemas sociais, com a inclusão da sociedade civil no processo de escolha das políticas públicas. (2018, p.85) 
O Decreto $\mathrm{n}^{\text {o }} 9.759$ de 11 de abril de $2019^{4}$, criado com o objetivo de "extinguir e estabelecer diretrizes, regras e limitações para colegiados da administração pública federal”, constitui-se como mais uma medida adotada pelo Estado na contramão dos avanços sociais. Sob essa questão, os conselhos podem ter maiores dificuldades para a efetivação dos direitos constitucionais, prevalecendo os interesses do mercado. Diante disso, fica evidente uma lógica que busca aumentar o poder governamental, com repercussões nas condições de vida da classe trabalhadora e no exercício da democracia participativa.

Nesse processo de ofensiva neoliberal e mercantilização das políticas sociais, o controle social representa um importante mecanismo democrático, todavia, persistem algumas dificuldades para o seu exercício. Nesse sentido, dentre os maiores problemas que inviabilizam um controle social real e efetivo está a baixa participação da sociedade civil. Além disso, podemos notar, ainda, a existência de relações clientelísticas na esfera política na medida em que a assistência social ainda é vista como um favor ou tutela. Como indica Castro:

(...) elementos recorrentes a uma prática assistemática, como o clientelismo, assistencialismo, patrimonialismo, benemerência, além do primeirodamismo, da filantropia e caridade, fazem parte da história da assistência social brasileira, mesmo após a incorporação do status de política pública de direito social. (2018, p.137)

Dessa forma, para enfrentar os desafios atuais no campo das políticas sociais, a exemplo da redução orçamentária na área social, é de grande importância a participação da população em arenas deliberativas como os conselhos, com vistas à criação de ações e políticas públicas inclusivas. Neste contexto, o controle social constitui-se como uma possibilidade de resistência para mudanças que sejam, de fato, democráticas.

\section{Considerações finais}

A partir das bases teóricas estudadas, é possível perceber que a política de assistência social, com o desenvolvimento do neoliberalismo, tem apresentado restrições, tanto em sua base orçamentária para a execução dos programas e serviços, quanto nas questões econômicas

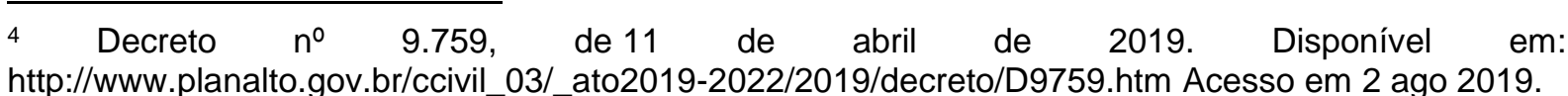


de reordenamento do capital. Isso tem repercutido nas formas de organização e participação da classe trabalhadora.

Nesse contexto de crise do capital, podemos notar que o Estado deixa de ser o responsável direto pelo desenvolvimento social para se tornar o promotor e regulador, transferindo para o terceiro setor suas atividades. Podemos notar um processo de privatização e focalização das políticas sociais bem como dificuldades para a concretização da efetiva participação popular no âmbito dos conselhos.

Destarte, pode-se perceber que o Estado prioriza a reprodução do capital em detrimento dos direitos constitucionais, o que se reflete na política de assistência social que passa por restrições no seu financiamento, com o desmonte dos serviços, além do processo de despolitização da sociedade civil. Frente a isso, temos um distanciamento dos direitos humanos e do contexto de cidadania na realidade brasileira.

Em síntese, consideramos que a ampliação da participação popular, na "gestão das políticas públicas no sentido de controlá-las" é fundamental para que se possa garantir, "cada vez mais, as necessidades e as demandas sociais e os interesses da coletividade" (Correia, 2006, p.145). Portanto, com o avanço do projeto neoliberal, torna-se necessário o processo de resistência e organização da classe trabalhadora, para o aprimoramento das políticas públicas e o fortalecimento do Estado democrático de Direito. 


\section{Referências bibliográficas}

BRASIL. Ministério do Desenvolvimento Social e Combate à Fome. LOAS - Lei Orgânica da Assistência Social Anotada. Brasília, 2009. Disponível em: https://fpabramo.org.br/acervosocial/wp-content/uploads/sites/7/2017/08/047.pdf.

BRASIL. Constituição da República Federativa do Brasil: texto constitucional promulgado em 5 de outubro de 1988, com as alterações determinadas pelas Emendas Constitucionais de Revisão nos 1 a 6/94, pelas Emendas Constitucionais nos 1/92 a 91/2016 e pelo Decreto Legislativo no 186/2008. Brasília: Senado Federal, Coordenação de Edições Técnicas, 2016.

BRASIL. Emenda Constitucional $\mathrm{n}^{\circ}$ 95, de 15 de dezembro de 2016. Altera o Ato das Disposições Constitucionais Transitórias para instituir o Novo Regime Fiscal e dá outras providências. Disponível em: http://www.planalto.gov.br/ccivil_03/constituicao/Emendas/Emc/emc95.htm Acesso em: 8 ago 2019.

BRAVO, Maria Inês de Souza e; CORREIA, Maria Valéria Costa. Desafios do controle social na atualidade. Serviço Social \& Sociedade., n.109, p.125-50, mar 2012.

CASTRO, Márcia da Silva Pereira. A política pública de assistência social e o estado brasileiro: assistencialismo, universalização ou focalização? Natal: EDUFRN, 2018.

CARNEIRO, André Pereira; GAMBI, Thiago Fontelas Rosado. Neoliberalismo, desigualdade e democracia: discussão fundamentada nos conselhos econômicos e sociais. Cadernos Gestão Pública e Cidadania. v.23, n.74, abr 2018. Disponível em: http://bibliotecadigital.fgv.br/ojs/index.php/cgpc/article/view/68697/71541 Acesso em 27 jun 2019.

CORREIA, Maria Valéria Costa. Que Controle Social? Os conselhos de saúde como instrumento. Rio de Janeiro: Editora Fiocruz, 2003.

- Controle Social na Saúde. In: MOTA, Ana Elizabete et al. Serviço Social e Saúde: Formação e trabalho profissional. São Paulo: Cortez, 2006.

COUTINHO, Carlos Nelson. Gramsci: um estudo sobre seu pensamento político. 4.ed. Rio de Janeiro: Civilização Brasileira, 2012.

DURIGUETTO, Maria Lúcia. Sociedade Civil e Democracia: um debate necessário. São Paulo: Cortez, 2008.

KATZ, Claudio. Neoliberalismo, neodesenvolvimentismo, socialismo. São Paulo: Expressão Popular / Fundação Perseu Abramo, 2016.

MACHADO, Loiva Mara de Oliveira. Controle Social da Política de Assistência Social: caminhos e descaminhos. Porto Alegre: EDIPUCRS, 2012. 
MOTA, Ana Elizabete. (Org.). Desenvolvimentismo e construção de hegemonia: crescimento econômico e reprodução da desigualdade. São Paulo: Cortez, 2012.

RAICHELLIS, Raquel. O Controle Social Democrático na Gestão e Orçamento Público 20 Anos Depois. In: Seminário Nacional O Controle Social e a Consolidação do Estado Democrático de Direito - CFESS (org.). Brasília: Conselho Federal de Serviço Social, 2011.

IBGE. Síntese de indicadores sociais: uma análise das condições de vida da população brasileira. Coordenação de População e Indicadores Sociais. Rio de Janeiro: IBGE, 2018. Disponível em: https://biblioteca.ibge.gov.br/visualizacao/livros/liv101629.pdf Acesso em 8 ago 2019.

SILVA, Mendes Mossicleia. A política de assistência social brasileira e o "neodesenvolvimentismo": notas ao debate. SER Social, v.16, n.35, p.377-400, jul/dez 2014.

SOUSA, Aione Maria da Costa. O Público e o Privado no Sistema de Saúde em Mossoró$R N$ : as contradições para a efetivação da universalidade. Recife: UFPE, 2013.

YAZBEK, Maria Carmelita. Pobreza e exclusão social: expressões da questão social no Brasil. Temporalis, Brasília, n.3, 2007. 